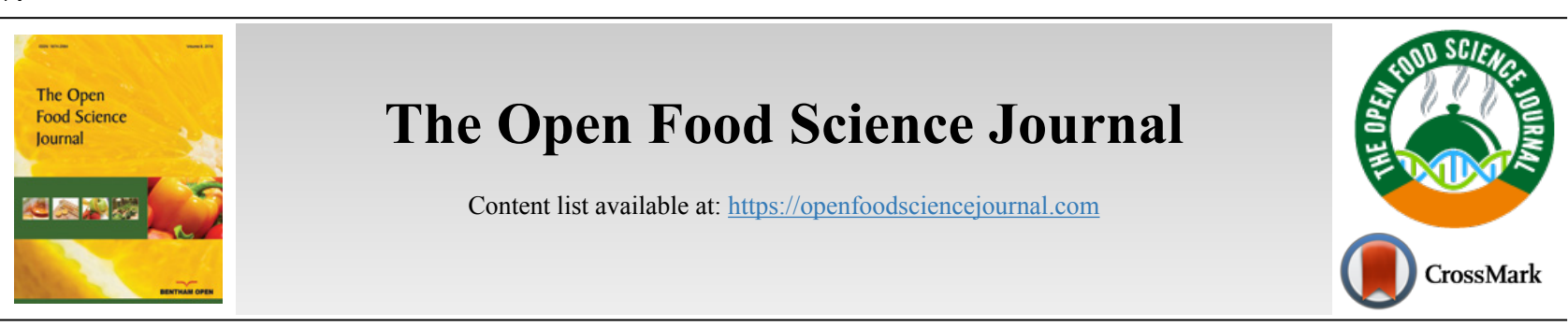

RESEARCH ARTICLE

\title{
Optimization of Head Space Pressure Using Liquid Nitrogen in Hot-packed BBQ Sauce
}

\author{
Praveen Yerramsetti ${ }^{1}$, Timothy Bowser ${ }^{2, *}$ and Ranjith Ramanathan ${ }^{1}$ \\ ${ }^{1}$ Department of Animal and Food Sciences, Oklahoma State University, Stillwater, OK, USA \\ ${ }^{2}$ Department of Biosystems Engineering, Oklahoma State University, Stillwater, OK, USA
}

\begin{abstract}
:
Introduction:

BBQ sauce was hot-filled at $54^{\circ} \mathrm{C}\left(130^{\circ} \mathrm{F}\right)$ in plastic PET, $567 \mathrm{~g}(20 \mathrm{oz})$ bottles. The PET bottles paneled, due to the temperature and pressure of the hot-fill process. Liquid nitrogen was used as a processing aid to optimize the headspace pressure to prevent paneling.

Objective:

The objective of the research was to eliminate paneling of the PET bottles due to hot-filling.

Methods:

A micro dosing system was used to inject nitrogen into the container just after filling and immediately prior to capping. Headspace pressure was measured using a custom-designed pressure sensor. Nitrogen dosage time was plotted against headspace pressure. The relationship between nitrogen dosage time and headspace pressure was linear, with a coefficient of determination of 0.84 , and slope of $1.36 \mathrm{kPa} / \mathrm{ms}$, with an intercept of $-12.21 \mathrm{kPa}$.

\section{Results \& Conclusion:}

Results were analyzed using analysis of variance. Visual inspection of the bottles for defects resulted in the determination of the optimum headspace pressure of $30 \mathrm{kPa}(4.4 \mathrm{psi})$.
\end{abstract}

Keywords: BBQ sauce, Headspace, Pressure, Paneling, PET bottle, Optimize.

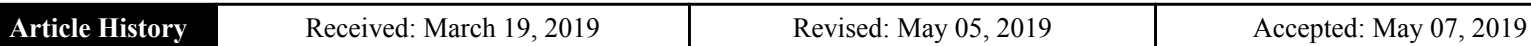

\section{INTRODUCTION}

Food manufacturing plants are considering the use of plastic packaging in place of glass bottles to help reduce costs, and enhance worker safety. Shipping costs are significantly reduced for plastic containers compared to glass because of the weight difference. Glass containers weigh about 7 times more than a similar plastic container (274 grams versus 39 grams). In some cases, plastic containers can be manufactured on site, further reducing shipping costs. Both glass and plastic may be re-cycled, but glass requires more energy to produce and recycle [1]. Furthermore, glass is brittle compared to plastic and is prone to breakage during manufacturing operations like receiving, production and shipping. Broken glass is an

* Address correspondence to this author at the Oklahoma State University 148 FAPC, Stillwater, OK 74078, USA; Fax: 405-744-6313; Tel: 405-744-6688; Email: bowser@okstate.edu adulterant in food products and a potential safety hazard to plant, personnel and consumers.

Plastic bottles have enormous benefits for packaging foods, but these benefits have not been realized for most hot-packed items like BBQ sauce. The hot-packing process poses container deformation issues resulting from the relatively high filling temperatures (compared to cold pack) and the headspace vacuum. The high temperatures and forces on the container resulting from the vacuum combine to deform the bottle. Deformation of plastic bottles due to heat and pressure is known as "paneling" in the industry (Fig. 1). The aim of this study was to use liquid nitrogen as a processing aid to optimize the headspace pressure in PET bottles filled with BBQ sauce. Liquid nitrogen may be classified as a processing aid in this case, is inert, and safe for consumers. 


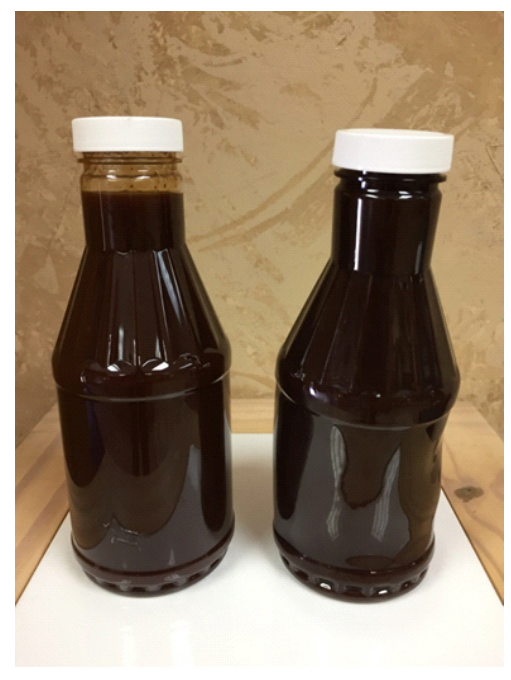

Fig. (1). Ordinary plastic bottle of BBQ sauce (left) and paneled (deformed) plastic bottle of BBQ sauce (right).

The demand for processed food with a longer shelf life is continuously growing. New methods of packaging are in use and being developed to accommodate longer shelf life. Newer packing methods include aseptic, hot filling [2] and modified atmosphere packaging (MAP). MAP uses combinations of gases like nitrogen, oxygen and carbon dioxide, depending on the food products packaging material and configuration.

Nitrogen gas purging of packaging headspace is a prominent method that has been widely used to help preserve beverages, meat and snacks. Nitrogen is also used in processing and packaging fresh cut and minimally processed vegetables and fruits [3,4] almonds [5] and herbs [6].

The role of bottling is significant in the BBQ sauce manufacturing process. It provides convenience for shipping and handling, however, due to the nature of the hot filling operation, paneling has prevented the use of more economic and safer plastic containers over glass. The result of paneling is an aesthetically unappealing bottle with a distorted shape that further results in wrinkled labels. Paneling is commonly observed in the plastic bottles that are hot filled and sealed prior to cooling [7]. There are two common solutions to paneling. The first is to use a rigid container. The rigid container must be strong enough to withstand the forces of the vacuum, which occurs from hot filling, without visibly yielding. Glass, steel and aluminum are examples of rigid containers. The second solution to paneling is to pressurize the container with an inert gas, like nitrogen. The pressurizing gas has the opposite effect of the vacuum, and can reduce or eliminate the vacuum, or pressurize the container. If the headspace pressure is too high, the bottle or its seal may burst, with the potential to spill the BBQ sauce into the environment, or on the consumer.

Oxygen present in the headspace can react with the product and alter the organoleptic properties like color. Liquid nitrogen dosing reduces the oxygen content in the headspace by displacing it. The reduced oxygen atmosphere in the bottle helps to enhance the quality and shelf life of the product [8].

While extensive research and development has been conducted on the use of nitrogen gas and MAP in food packaging [9 - 11], information on the use of liquid nitrogen gas filling for hot-packing of BBQ sauce has not been published. The objective of this research was to determine the optimum dose of liquid nitrogen required to overcome paneling of the plastic container.

\section{MATERIALS AND METHODS}

The experiment was conducted at a BBQ sauce production plant in Oklahoma. Fig. (2) describes the process flow of the experiment.

Freshly made BBQ sauce from the production line at Head Country, Inc., Ponca City, Oklahoma, USA was provided for the experiment. The BBQ sauce was filled into custom-made plastic PET bottles (VPet, Garland, USA. Fill mass was 567 grams $(20 \mathrm{oz})$. Fill temperature was $54^{\circ} \mathrm{C}(130 \mathrm{~F})+/-2{ }^{\circ} \mathrm{C}$, which was monitored using a calibrated thermometer. Immediately after filling, a dosage of liquid nitrogen was deposited into the head space of the bottle using the automated Nitrodose System (model MD 157, Vacuum Barrier Corporation, Woburn, USA). The automated nitrogen dosage system had the capability to control the timing of the liquid nitrogen dosage application to $25,26,28,30,32,34$ and $36 \mathrm{~ms}$. An image of a container of BBQ sauce receiving a dose of nitrogen is shown in Fig. (3).

After the dosage, the bottles passed through an induction sealer where heat, generated by an eddy current, sealed a foil disk laminated with plastic to secure the bottles (Fig. 3)

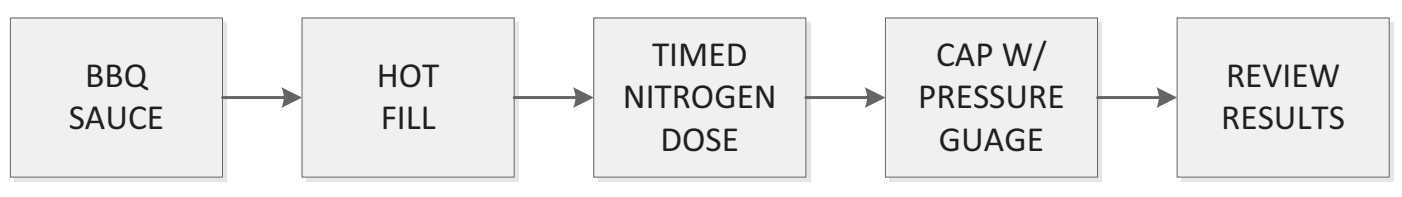

Fig. (2). Process flow of experimental setup. 


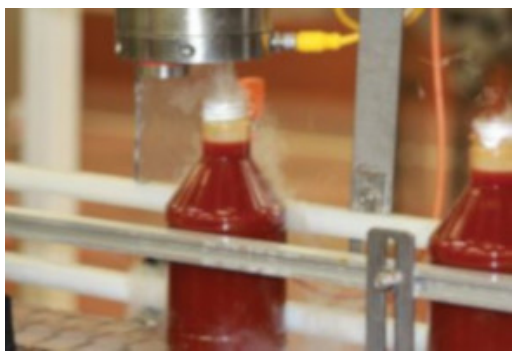

Fig. (3). Nitrogen gas dosed into a container of BBQ sauce just after hot filling.

The head space pressure of the bottles was measured using a touch type gauge (model 1706210252, SSI technologies, Janesville, USA). The gauge was mounted on a screw type metal lid (Figs. 4 and 5) which was directly placed by hand on the BBQ bottle after the dose of liquid nitrogen was applied.

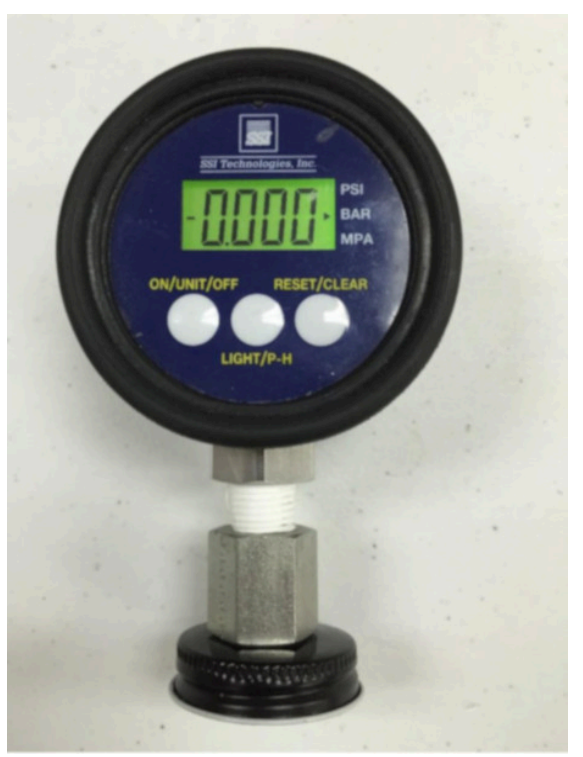

Fig. (4). Pressure gauge integrated with container cap to measure headspace pressure of a bottle.

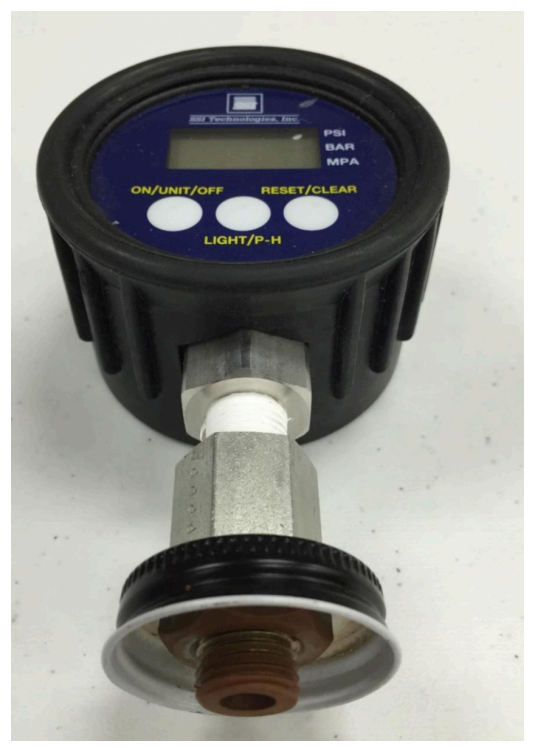

Fig. (5). Detail of pressure guage sensor attachment to a screw-on container cap.

Pressure readings from the dosage times starting from $25 \mathrm{~ms}$ to $36 \mathrm{~ms}$ were recorded and analyzed to identify the optimum head space pressure.

A minimum of five replicates per dosage were recorded and analyzed as shown in Table $\mathbf{1}$.

Observation was used to determine the optimal headspace pressure for the filled BBQ sauce bottles. The key factors observed were:

(1) Deformed or paneled containers

(2) Label application and appearance of the applied label.

(3) Shape of the seal on the finished product after the product cooled to room temperature.

Table 1. Headspace pressure (kpa), measured at given liquid nitrogen dose times (ms) for bbq sauce filled into pet bottles at $54^{\circ} \mathrm{c}$.

\begin{tabular}{|c|c|c|c|c|c|c|c|}
\hline \multirow{2}{*}{ Observation } & \multicolumn{9}{|c|}{ Nitrogen Dose Time, ms } \\
\cline { 2 - 8 } & $\mathbf{2 5}$ & $\mathbf{2 6}$ & $\mathbf{2 8}$ & $\mathbf{3 0}$ & $\mathbf{3 2}$ & $\mathbf{3 4}$ & $\mathbf{3 6}$ \\
\hline 1 & 22.75 & 20.89 & 25.03 & 35.16 & 29.85 & 35.16 & 34.61 \\
\hline 2 & 21.37 & 19.58 & 25.23 & 26.82 & 33.99 & 35.44 & 34.13 \\
\hline 3 & 20.68 & 23.17 & 21.93 & 30.13 & 33.65 & 35.30 & 35.16 \\
\hline 4 & 25.51 & 25.03 & 23.79 & 32.96 & 31.99 & 33.23 & 34.34 \\
\hline 5 & 21.44 & 22.55 & 27.92 & 26.48 & 35.03 & 34.13 & 35.16 \\
\hline 6 & 18.82 & 21.10 & 24.20 & 31.51 & 31.99 & - & 34.34 \\
\hline 7 & 21.03 & - & - & - & - & - & - \\
\hline Average & 21.66 & 22.05 & 24.68 & 30.51 & 32.75 & 34.65 & 34.62 \\
\hline Std. Dev. & 2.06 & 1.93 & 1.98 & 3.43 & 1.85 & 0.95 & 0.45 \\
\hline
\end{tabular}




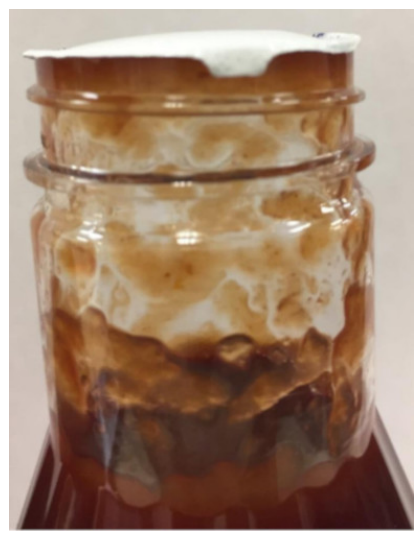

Fig. (6). Convex seal resulting from excessive headspace pressure due to the liquid nitrogen dose.

Label application and appearance were evaluated as acceptable if the label around the bottle was uniform. Shape of the foil seal was also considered in determining the optimum pressure. A bulged appearance (convex shape), as shown in Fig. (6), was rated as unacceptable.

\section{RESULTS}

A scatter plot and best-fit line for the data provided in Table 1 were made using JMP 14 (SAS institute, Cary, USA) and shown in Fig. (7). The line of best fit had a coefficient of determination $\left(\mathrm{r}^{2}\right)$ of 0.84 , with a y-intercept of $-12.21 \mathrm{kPa}$ and a slope of $1.36 \mathrm{kPa} / \mathrm{ms}$. The slope indicated that the container headspace pressure increased $4.24 \mathrm{kPa}$ for each $\mathrm{ms}$ and the nitrogen dispensing valve was open (within the range of 25 to $36 \mathrm{~ms}$ ).

The use of liquid nitrogen while filling BBQ sauce into plastic bottles enabled the processor to replace glass bottles with plastic. The replacement of glass bottles with plastic resulted in a tremendous cost savings, as shown in Table $\mathbf{2}$. In 2017 , the company produced a total of 3,205,137 bottles of BBQ sauce in plastic containers, which resulted in a savings of $\$ 1,171,658$ over packaging in glass containers.

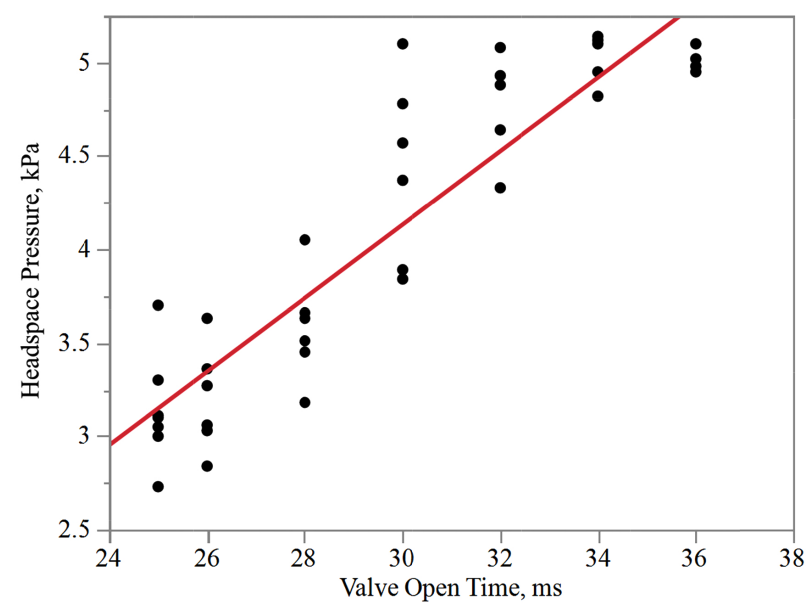

Fig. (7). Scatter plot with liquid nitrogen valve open time (ms) versus head space pressure $(\mathrm{kPa})$.
Table 2. Costs savings in 2017 realized by converting from glass to plastic.

\begin{tabular}{|c|c|c|}
\hline Savings & $\mathbf{5 6 7}$ g Bottles & $\mathbf{1 1 3 4}$ g Bottles \\
\hline Materials (glass to plastic) & $\$ 556,942$ & $\$ 415,328$ \\
\hline Freight & $\$ 112,741$ & $\$ 86,647$ \\
\hline Total & $\$ 669,683$ & $\$ 501,975$ \\
\hline Per bottle packed & $\$ 0.3267$ & $\$ 0.4345$ \\
\hline
\end{tabular}

\section{DISCUSSION}

A linear relationship was demonstrated between the time that the nitrogen valve was open and the resulting headspace pressure of hot-filled, sealed, PET BBQ sauce containers. PET BBQ sauce bottles which did not receive a dosage of liquid nitrogen, or had a headspace pressure less than $30 \mathrm{kPa}$, appeared deflated. The deflated appearance was determined by inspecting the bottles on the line for paneling and viewing applied labels for unacceptable deformity. Analysis of the data and bottles revealed that the optimum range for headspace pressure was $30 \mathrm{kPa}(4.35 \mathrm{psi})$. The bottles with a headspace pressure higher than $32 \mathrm{kPa}$ (4.64 psi) resulted in a convex foil seal (Fig. 6) and an undesirable spray of sauce upon opening the foil seal of the bottle.

\section{CONCLUSION}

The optimum pressure for bottle headspace was determined to be $30 \mathrm{kPa}$. While various pressures ranging from $19 \mathrm{kPa}$ to $35 \mathrm{kPa}$ were investigated, the lower pressure deflated the bottle while the higher pressures lead to an uneven seal on the bottle. This novel approach of pressurizing the headspace with a liquid nitrogen made it possible to convert from glass to plastic bottles for hot-filling BBQ sauce. The increased headspace pressure eliminated the deformation challenges associated with hot-filling PET bottles. Furthermore, successful conversion to PET bottles eliminated safety concerns of glass in the production facility and reduced costs.

\section{ETHICS APPROVAL AND CONSENT TO PARTI- CIPATE}

Not applicable.

\section{HUMAN AND ANIMAL RIGHTS}

No animals/humans were used for studies that are the basis of this research.

\section{CONSENT FOR PUBLICATION}

Not applicable.

\section{AVAILABILITY OF DATA AND MATERIALS}

Not applicable.

\section{FUNDING}

None.

\section{CONFLICT OF INTEREST}

The authors declare no conflict of interest, financial or otherwise. 


\section{ACKNOWLEDGEMENTS}

The authors gratefully acknowledge the support by Mr. Rocky Flick, CEO Head Country BBQ Inc. for funding this project. We would also like to thank Mr. Alan Slater for customizing the liquid nitrogen gauge and assisting in troubleshooting the experiment without which this project would have not been accomplished. We also acknowledge the valuable support and administrative leadership provided by the R.M. Kerr Food \& Ag Products Center at Oklahoma State University, USA.

\section{REFERENCES}

[1] Bruce H. A study of the beverage industry. System energy and recycling. Thesis submitted to University of Illinois UrbanaChampaign. 1973.

[2] Manfredi M, Vignali G. Comparative life cycle assessment of hot filling and aseptic packaging systems used for beverages. J Food Eng 2015; 147: 39-48

[http://dx.doi.org/10.1016/j.jfoodeng.2014.09.018]

[3] Koseki S, Isobe S. Prediction of pathogen growth on iceberg lettuce under real temperature history during distribution from farm to table. Int J Food Microbiol 2005; 104(3): 239-48.

[http://dx.doi.org/10.1016/j.ijfoodmicro.2005.02.012] [PMID: 15979
180]

[4] Rodríguez-Hidalgo S, Artés-Hernández F, Gómez PA, Fernández JA, Artés F. Quality of fresh-cut baby spinach grown under a floating trays system as affected by nitrogen fertilisation and innovative packaging treatments. J Sci Food Agric 2010; 90(6): 1089-97.

[http://dx.doi.org/10.1002/jsfa.3926] [PMID: 20355151]

[5] Raisi M, Ghorbani M, Sadeghi Mahoonak A, et al. Effect of storage atmosphere and temperature on the oxidative stability of almond kernels during long term storage. J Stored Prod Res 2015; 62: 16-21. [http://dx.doi.org/10.1016/j.jspr.2015.03.004]

[6] Wenzhong HU, Xu P, Toshitaka U. Extending storage life of fresh gingseng by modified atmosphere packaging. J Sci Food Agric 2005; 85: $2475-81$.

[http://dx.doi.org/10.1002/jsfa.2282]

[7] Berk O. Plastic Bottle Paneling: 5 causes and the cures Available at: http:// www.oberk.com /packaging-crash-course / plastic-bottlepaneling-5-causes-and-the-cures-2018.

[8] Ansari IA, Datta AK. An overview of sterilization methods for packaging materials used in aseptic packaging systems. Food Bioprod Process 2003; 81: 57-65.

[http://dx.doi.org/10.1205/096030803765208670]

[9] Zenger RD, Cornell SW, Schneiders J. Method of packaging products in plastic containers US Patent 5, 251, 424, 1993.

[10] Andison D, Scheffer S. Method of supporting plastic containers during product filling and packaging when exposed to elevated temperatures and internal pressure varaitions US Patent 6, $502,369,2003$.

[11] Fisher TJ. Multiple-atmosphere, nested food container US Patent Application 0307116 A1, 2010.

(C) 2019 Yerramsetti et al.

This is an open access article distributed under the terms of the Creative Commons Attribution 4.0 International Public License (CC-BY 4.0), a copy of which is available at: https://creativecommons.org/licenses/by/4.0/legalcode. This license permits unrestricted use, distribution, and reproduction in any medium, provided the original author and source are credited. 